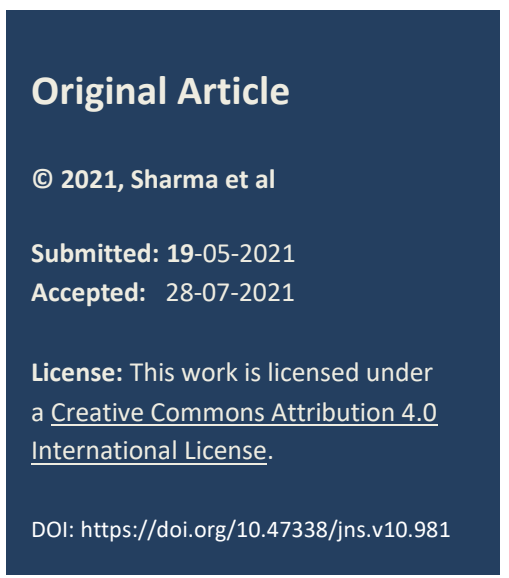

\title{
Erudition after neonatal gastric transposition for esophageal atresia at 10 years of
} follow-up

Kanika Sharma, Shilpa Sharma," Devendra Kumar Gupta

Department of Pediatric Surgery, All India Institute of Medical Sciences, New Delhi, India

Correspondence*: Dr. Shilpa Sharma, Additional Professor, Department of Pediatric Surgery. Room no. 4002, 4th floor, Academic Block, All India Institute of Medical Sciences, New Delhi-110029, India.

E-mail: drshilpas@gmail.com

\section{KEYWORDS \\ Esophageal replacement, Gastric transposition, Neonate, \\ Gastric pull up}

\begin{abstract}
Background: Gastric transposition (GT) is a well-established procedure of esophageal replacement (ER) for children with esophageal atresia. ER in the neonatal period is sparsely reported. We report characteristics of children who have undergone neonatal GT and have completed ten years of follow-up.
\end{abstract}

Methods: The cross-sectional study was conducted which included all children who underwent neonatal GT at the institute and have completed a follow-up of at least 10-years. Anthropometry, oral contrast study, Hepatobiliary Scintigraphy, Gastroesophageal reflux study, Gastric emptying test, spirometry, and blood investigations were done for all the children.

Results: Four children (three male and one female) were included in the study. The mean age at ER was $5.3 \pm 2.2$ days with a mean birth-weight of $2.43 \pm 0.13 \mathrm{~kg}$. Two children had primary GT, while the other two had GT following a leak in primary anastomosis. During the mean follow-up of $180.25 \pm 43.5$ months, none of the children required esophageal dilatation or other surgical intervention or procedures. All children were below 3rd centile for weight-forage while all except one were below 50th centile for height-for-age. There was no stricture on oral contrast study, however, one child had grade III reflux on GER scan. Persistent duodenogastric reflux on HIDA scan was seen in one child. Three children had restrictive parameters on spirometry. Symptomatically, all reported poor weight gain, one had left vocal cord palsy with hoarseness, and one had chest-wall protuberance.

Conclusions: Neonatal gastric transposition is a feasible alternative to delayed esophageal replacement for neonates with esophageal atresia with limited complications.

\section{INTRODUCTION}

The management of Esophageal atresia has always been a challenge. The survival of these babies depends on birth weight, early diagnosis, associated anomalies, pre-operative stabilization, and postoperative care.

The contemporary approach is to preserve the native esophagus by attempting a primary anastomosis, even in moderate-severe tension.[1] However, when the primary anastomosis is not possible, either a serial lengthening procedure followed by delayed primary repair is opted or esophageal diversion with subsequent esophageal replacement (ER) at a later date is considered. Various options are available for ER including gastric transposition (GT), gastric tube, colonic interposition, ileal or jejunal micro anastomo- sis.[2,3] However, attempt for neonatal esophageal replacement (ER) is sparsely reported.[4,5]

We report characteristics of children who had undergone GT in the neonatal age at our center and have a minimum follow-up of ten years. With this study, authors attempt to emphasize the long-term results of neonatal ER and thus, define the safety and feasibility of neonatal ER.

\section{METHODS}

All the children who had undergone neonatal ER by a single senior surgeon (DKG) for esophageal atresia with or without trachea-esophageal fistula and have completed a minimum ten years of follow-up were included. They were enrolled from the Pediatric surgery clinic at All India Institute of Medical Sciences, 
New Delhi, India from 01 July 2018 to 30 June 2019, after ethical approval by the Institutional review board. Parental informed consent and assent were taken from all parents and participants respectively. Refusal to participate in the study or failure to visit clinic for follow-up were taken as exclusion criteria.

The records of all participants were accessed for documentation of their baseline characteristics and they were subjected to follow-up assessments during the study period. Anthropometric assessment, including height in centimeters, weight in kilograms, and bodymass-index in $\mathrm{kg} / \mathrm{m} 2$ was done. IAP (Indian Association of Pediatrics) growth charts were used as a reference and the value between the 3rd to 97th centile was considered normal.[6] Oral contrast swallow was done using diluted Diatrizoate meglumine $(1: 1)$ to evaluate the characteristics of the conduit including narrowing or stricture, hold-up of contrast, and distal drainage. The Hepatobiliary Scintigraphy (HIDA) scan with 99m-Tc mebrofenin, while Gastroesophageal reflux (GER) study and Gastric emptying test (GET) study with $99 \mathrm{~m}-\mathrm{Tc}$ sulphur colloid nuclear-tracers were done to assess duodenogastric reflux (DGR), GER, and gastric emptying, respectively. Pulmonary function test was performed using a PC spirometer where Forced vital capacity (FVC) and Forced expiratory volume in 1 second (FEV1) were documented. Blood sample (approx. $5 \mathrm{ml}$ ) was withdrawn to assess the hemoglobin, total protein, albumin, ferritin, transferrin, serum folate, and vitamin B12 levels. Functional Oral Intake Scale (FOIS) by Crary et al was utilized to assess eating habits and dysphagia.[7]

Descriptive statistics were applied in the study. The data entry has been done using Microsoft Excel version 16.50. Statistical analysis was done using SPSS 24 (SPSS, Inc., Chicago, Illinois, USA). Data are expressed as Mean \pm Standard deviation and median (with interquartile range IQR1 and IQR3) values.

\section{RESULTS}

\section{Baseline characteristics:}

Four children (Male: Female 3:1) with a mean birth weight of $2.43 \pm 0.13 \mathrm{~kg}$, underwent ER with Gastric transposition (GT) in the neonatal period at the mean age of $5.3 \pm 2.2$ days (Table 1 ). One of them had associated patent ductus arteriosus (PDA) and pyloric atresia, while the other had associated PDA only. Two children, one with pure EA (Gross type A) and the other with EA-TEF (Gross type C), had undergone primary GT. The other two children with EA-TEF (Gross type C) had undergone primary anastomosis and had a major leak in the mediastinum, following which ER with GT was done on postoperative days 3 and 4 , respectively. The trans-hiatal route was considered in three children while the retrosternal route was chosen in one. One of them had a cervical anastomosis leak in the post-operative period and required prolonged mechanical ventilation and diagnostic bronchoscopy with bronchial lavage in the postreplacement period. None of the children required esophageal dilatation in the post-operative period.

\section{Follow-up characteristics:}

The mean duration of follow-up in our series was $180.25 \pm 43.5$ months following ER. No other surgical procedure or intervention was required for any child during the follow-up period. The following characteristics were observed during the follow-up:

a) Anthropometry: The median height was $151 \mathrm{~cm}$ and the median weight was $25 \mathrm{~kg}$ at a median age of 15.2 years (Table 2). All the children were below the 3rd centile for weight-for-age (Fig.1). One child (25\%) had height-for-age above 50th centile, while the other three were less than 50th centile but more than 3rd centile for height-for-age. All had BMI less than 3rd centile for age.

b) Oral contrast swallow study: Healthy conduit was noted in all. There was no stricture or narrowing in any child. However, two children showed hold-up of contrast in the intrathoracic stomach with complete delayed clearance from the transposed stomach (Fig. 2).

c) GER study: There was a prolonged accumulation of tracer in the intrathoracic stomach of two of the children. One other child had grade III GER reflux.

d) HIDA scan: One child demonstrated the persistent DGR on sequential HIDA scans. However, another child who had revealed DGR in the previous scan had resolution of DGR on the latest follow-up scan.

e) Gastric emptying time study: All the children had normal gastric emptying on follow-up with a mean percentage of emptying being $93.5 \pm 6.8 \%$ in mean half-time of $28.7 \pm 13.1$ minutes.

f) Pulmonary Function test: Three children (75\%) revealed a restrictive pattern on spirometry. However, none of them had any grade of dyspnea, nor required bronchodilators.

g) Nutritional assessment: The assessments of hemoglobin, total protein, albumin, serum folate, and vitamin B12 were normal for all four children (Table 3). However, the mean value of serum ferritin levels of the series was $14.0 \pm 10.8 \mathrm{ng} / \mathrm{ml}$ with two children having serum ferritin of less than $10 \mathrm{ng} / \mathrm{ml}$.

h) Symptoms on recent follow-up visit: Parents of all children reported a poor weight gain in comparison to their siblings. Three children had no dysphagia or dietary restrictions and thus were stated as FOIS level 7 while one patient occasionally complained of difficulty in swallowing hard consistency food and pre- 
ferred soft consistency food (FIOS level 5). As per the academic recall, two children were good in academics, while the other two were average in their studies. One child had hoarseness, recurrent cough, and coryza due to left vocal cord palsy. However, overall activities were good and this child was excelling in sports activities. Another child, with chest wall bony protuberance following surgery, had body disfigurement concerns.

Table 1: Children with neonatal gastric transposition with follow-up more than 10 years

\begin{tabular}{|c|l|l|l|l|l|l|}
\hline S. no & Gender & $\begin{array}{l}\text { Gross classification } \\
\text { (type of esophageal } \\
\text { atresia) }\end{array}$ & $\begin{array}{l}\text { Birth } \\
\text { weight } \\
\text { (kg) }\end{array}$ & $\begin{array}{l}\text { Associated } \\
\text { anomalies }\end{array}$ & $\begin{array}{l}\text { Age (days } \\
\text { of life) at } \\
\text { ER }\end{array}$ & $\begin{array}{l}\text { Follow up } \\
\text { (months) }\end{array}$ \\
\hline $\mathbf{1}$ & Female & Type A & 2.3 & PDA & - & 4 \\
\hline $\mathbf{2}$ & Male & Type C & 2.6 & $\begin{array}{l}\text { Pyloric atresia } 1 \\
\text { and PDA }\end{array}$ & - & 3 \\
\hline $\mathbf{3}$ & Male & Type C & 2.4 & - & $\begin{array}{l}\text { Primary repair at } \\
3 \text { days of life }\end{array}$ & $\begin{array}{l}\text { Primary repair at } \\
4 \text { days of life }\end{array}$ \\
\hline $\mathbf{4}$ & Male & Type C & 2.4 & - & 8 \\
\hline
\end{tabular}

Type A- Pure Esophageal atresia; Type C- Distal Esophageal atresia with tracheoesophageal fistula; ER- Esophageal replacement; PDA- Patent ductus arteriosus

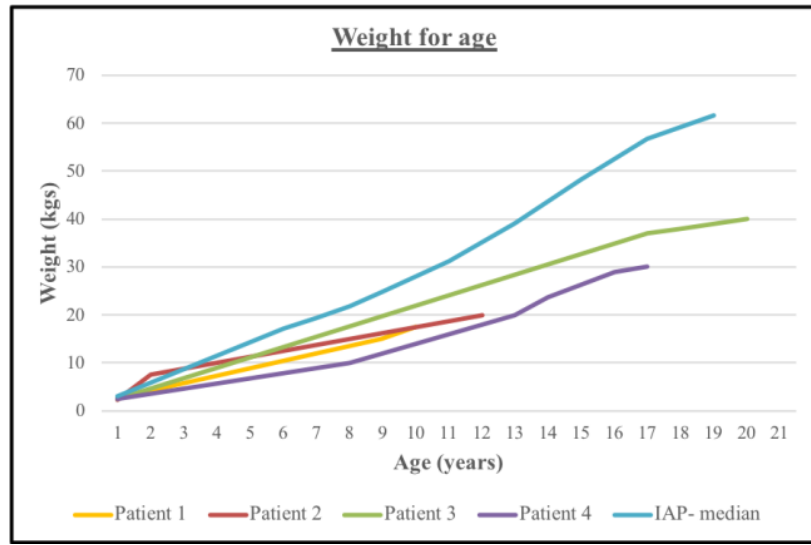

Figure 1: Weight for age plot of the children over follow-up period

Table 2: Anthropometric data at last follow up visit

\begin{tabular}{|l|l|}
\hline Age (months) & $188(141.8-229)$ \\
\hline Height (cm) & $151(134.2-161.7)$ \\
\hline Weight (kg) & $25(19-32.5)$ \\
\hline
\end{tabular}

All the values are expressed in median values (with interquartile range IQR1 and IQR3)

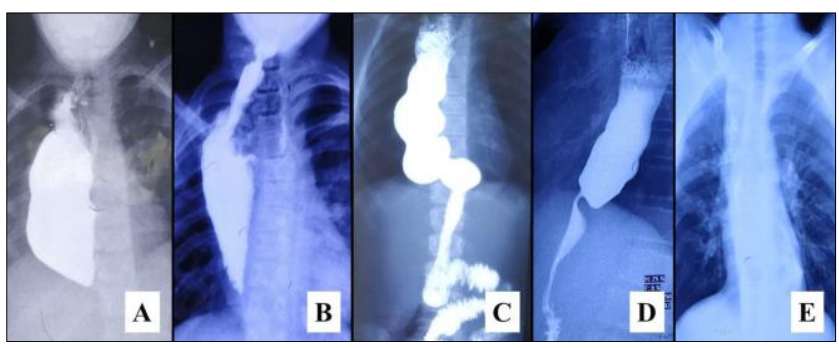

Figure 2: Oral contrast study (done during the study period) showing a healthy conduit in all the child.(A) Mild hold-up of contrast in pulled up stomach of 12-year child.(B) A normal caliber anastomosis between cervical esophagus and pulled up stomach is located in lower neck of 16-year child with free passage of contrast across it.(C) The elongated transposed stomach in the thorax in 10-year old child with normal passage of contrast.(D) 19-year old child with slow transit of contrast, however with complete contrast clearance (E) from transposed stomach
Table 3: Blood test values at last follow up visit

\begin{tabular}{|l|l|}
\hline Hemoglobin (gm/dl) & $11.9(10.5-13.2)$ \\
\hline Serum Ferritin (ng/ml) & $8.7(7.8-17.5)$ \\
\hline Serum Vitamin B12 (pmol/L) & $26.7(15.8-37.5)$ \\
\hline Serum Folate (ng/ml) & $7.5(7.3-8.6)$ \\
\hline Total protein (gm/dl) & $7.5(7.4-7.6)$ \\
\hline Serum albumin (gm/dl) & $5.2(5.1-5.3)$ \\
\hline
\end{tabular}

The neonates with esophageal atresia (with or without fistula) having long gap esophageal atresia are managed with common procedures like primary repair, diversion, delayed primary repair with or without lengthening procedures.[8,9] However, in the setting of a major leak following primary anastomosis, refractory stricture formation, or recurrent tracheoesophageal fistula, a diversion procedure with subsequent ER is the acceptable strategy.[1] Alternatively, these neonates can also be considered for a neonatal ER provided the leak is detected early and the general condition (especially the lung condition) of the child is favorable for major reconstructive surgery.

In our case series, all the children underwent gastric transposition in the neonatal period. GT was initially described by Lewis Spitz.[10] The favorable points for Neonatal GT are:[11]

1. Due to good vascularity and musculature of the stomach, the fundus of the stomach can be mobilized to the cervical region with ease.

2. This procedure utilizes single anastomosis i.e. cervical esophagogastric anastomosis. Thus, re- 
ducing the chances of the leak from long suturelines and multiple anastomoses.

3. The non-distended stomach of esophageal atresia can substitute for the esophagus of similar caliber conduit, thereby, lesser long-term respiratory problems of distended intrathoracic stomach.

4. This procedure can be done by laparotomy and cervical exploration. Thus, thoracotomy and its complications are avoided.

The primary ER has been done in esophageal atresia repair, with neonatal GT being the preferred method at various centers. $[4,5,12,13]$ It is favored in cases of Long-gap esophageal atresia and pure esophageal atresia.[14] A healthy newborn with favorable chest condition along with a well-experienced surgeon and availability of an advanced neonatal intensive care system remains the prerequisite for the success of the procedure. $[15,16]$

Long-term survivors of esophageal atresia have numerous challenges of the aerodigestive system. In our previous experience with GT, we have shown satisfactory long-term outcomes in children.[17] Gastroesophageal reflux (GER) is a common postoperative complication in patients with esophageal atresia ranging from $27 \%$ to $75 \%$ while with gastric transposition the incidence of reflux reaches as high as $100 \%$.[18,19] The contributory factors include the innate condition of the esophagus i.e. its innate dysmotility, damage to the vagus nerve, and anatomical changes due to surgical repair. Dysphagia has been documented as high as in around half of the patients with esophageal atresia and those who underwent gastric transposition.[18,20] Swallowing problems and dysphagia is a common post-ER complication, which is often attributed to anastomotic stricture or GER. A meta-analysis documented a $17.7 \%$ incidence of anastomotic stricture in gastric transposition.[21] While significant reflux was noted in one patient, none of the patients had dysphagia or anastomotic stricture in our series.

The abnormalities of gastric motility (delayed gastric emptying) are known as a delayed complication with GT.[22] To address this concern, pyloromyotomy or pyloroplasty are frequently performed as drainage procedures for efficient gastric emptying.[3,23] All our children of GT underwent a simultaneous drainage procedure with pyloromyotomy or pyloroplasty as the operating surgeon is a proponent for providing drainage procedures to GT due to the small lumen of the pylorus in children. This additional step also helped in the simultaneous management of a patient with pyloric atresia. In our series, while gastric emptying was normal for all the children, duodenogastric reflux (DGR) which is a known complication in GT and attributed to pyloroplasty or pyloromyotomy, was seen in one child. Other associated gastrointestinal complications with GT, i.e. dumping or rapid gastric emptying was not seen in any of the patients of our study.

The persistent pulmonary dysfunction in patients of esophageal atresia is suggested secondary to airway and lung damage due to repeated respiratory tract infection and GER.[24,25] Also, the incidence of respiratory morbidity is well-documented with all the procedures of ER, with a higher incidence in children who had undergone GT $(24.6 \%)$ when compared with other methods of ER.[20] It can be attributed to the transposition of the stomach in the mid-thorax, straightening of the gastroesophageal junction, thus promoting reflux. While these children develop the chronic pulmonary disease with normal lung functions in $23 \%$ to $48 \%$ of them, overall normal exercise tolerance with no or little limitation is observed in most of the children.[24]

Growth restriction and underweight are seen in patients of esophageal atresia beyond childhood. While weight averages around the 25th percentile for age, these patients do catch up height to normal distribution for age.[22] Similar growth patterns were observed during long follow-up periods in our series. The anemia and low stores of iron are documented with GT.[26] However, all patients in our series maintained normal hemoglobin levels, while two of them had low ferritin levels. Very few reports document the post-ER laryngeal nerve injury.[22,27] We had one case with laryngeal nerve injury following GT. Around $10 \%$ of patients with esophageal atresia have associated congenital skeletal anomalies, while following thoracotomy, the chest wall deformity, and vertebral abnormalities may vary from $14 \%$ to $47 \%$.[24] In our series, one child had rib prominences, but none of them had spinal deformities.

Patient selection is paramount for attempting the ER in neonates. The chest condition and cardiac anomalies should be well investigated, and stabilization of which should preclude the neonatal ER. The neonates with a good chest condition who have been detected to have early primary anastomotic leak can also be the candidates for neonatal ER.[16] The neonatal ER is a feasible option, the success of which depends on the expertise of the surgeon and availability of neonatal care. There is a dearth of literature on long-term outcomes of neonatal ER. However, the overall longterm functional outcome of GT remains good to excellent with minimal complication and unimpaired longterm quality of life.[28] In view of the assessment of a 10-year long follow-up period, the small sample size of the study remains the limitation. A multi-center trial with a larger number of children needs to be conducted before definite conclusions are drawn. With our study, we demonstrated satisfactory 10-year long-term outcomes with neonatal GT and thus, con- 
template and promote the implementation of neonatal ER. In a developing country like ours, where patients are lost to follow-up, this single-stage procedure with an outcome comparable to that of staged repair in long-gap esophageal atresia, can serve as a boon.

Acknowledgements: Nil.

Conflict of Interest: None

\section{REFERENCES}

1. Shieh HF, Jennings RW. Long-gap esophageal atresia. Semin Pediatr Surg. 2017; 26:72-7.

2. Kunisaki SM, Coran AG. Esophageal replacement. Semin Pediatr Surg. 2017; 26:105-15.

3. Sharma S, Gupta DK. Surgical techniques for esophageal replacement in children. Pediatr Surg Int. 2017; 33:527-50.

4. Zeng Z, Liu F, Ma J, Fang Y, Zhang H. Outcomes of primary gastric transposition for long-gap esophageal atresia in neonates. Medicine (Baltimore). 2017; 96:e7366.

5. Gupta DK, Sharma S. Esophageal substitution for esophageal atresia: experience with neonatal gastric transposition. Pediatr Health. 2008; 2:453-62.

6. Khadilkar V, Yadav S, Agrawal KK, Tamboli S, Banerjee M, Cherian A, et al. Revised IAP growth charts for height, weight and body mass index for 5- to 18-year-old Indian children. Indian Pediatr. 2015; 52:47-55.

7. Crary MA, Mann GD, Groher ME. Initial psychometric assessment of a functional oral intake scale for dysphagia in stroke patients. Arch Phys Med Rehabil. 2005; 86:151620

8. Spitz L. Oesophageal atresia. Orphanet J Rare Dis. 2007; $2: 24$.

9. Reusens H, Matthyssens L, Vercauteren C, van Renterghem K. Multicentre survey on the current surgical management of oesophageal atresia in Belgium and Luxembourg. J Pediatr Surg. 2017; 52:239-46.

10. Spitz L. Gastric transposition in children. Semin Pediatr Surg. 2009; 18:30-3.

11. Sharma S, Gupta DK. Primary gastric pull-up in pure esophageal atresia: technique, feasibility and outcome. A prospective observational study. Pediatr Surg Int. 2011; 27:583-5.

12. Holland AJA, Ron O, Pierro A, Drake D, Curry JI, Kiely EM, et al. Surgical outcomes of esophageal atresia without fistula for 24 years at a single institution. J Pediatr Surg. 2009; 44:1928-32.

13. Choudhury S, Yadav PS, Khan NA, Shah S, Debnath PR, Kumar V et al. Pediatric esophageal substitution by gastric pull-up and gastric tube. J Indian Assoc Pediatr Surg. 2016; 21:110.

14. Gupta DK, Sharma S. Esophageal atresia: the total care in a high-risk population. Semin Pediatr Surg. 2008; 17:23643.

15. Gupta DK, Sharma S, Arora MK, Agarwal G, Gupta M, Grover VP. Esophageal replacement in the neonatal period in infants with esophageal atresia and tracheoesophageal fistula. J Pediatr Surg. 2007; 42:1471-7.

\section{Source of Support: Nil}

Consent to Publication: Author(s) declared taking informed written consent for the publication of clinical photographs/material (if any used), from the legal guardian of the patient with an understanding that every effort will be made to conceal the identity of the patient, however it cannot be guaranteed.

Author Contributions: Author(s) declared to fulfil authorship criteria as devised by ICMJE and approved the final version.

16. Gupta D, Srinivas M, Agarwala S, Dave S, Arora M, Gupta A et al. Neonatal gastric pull up: reality or myth? Pediatr Surg Int. 2003; 19:100-3.

17. Jain V, Sharma S, Kumar R, Kabra SK, Bhatia V, Gupta DK. Transposed intrathoracic stomach: functional evaluation. Afr J Paediatr Surg. 2012; 9:210-6.

18. Shawyer AC, Pemberton J, Flageole H. Post-operative management of esophageal atresia-tracheoesophageal fistula and gastroesophageal reflux: A Canadian Association of Pediatric Surgeons annual meeting survey. J Pediatr Surg. 2014; 49:716-9.

19. Garritano S, Irino T, Scandavini CM, Tsekrekos A, Lundell L, Rouvelas I. Long-term functional outcomes after replacement of the esophagus in pediatric patients: A systematic literature review. J Pediatr Surg. 2017; 52:1398408.

20. Acher C, Ostlie D, Leys C, Struckmeyer S, Parker M, Nichol P. Long-term outcomes of patients with tracheoesophageal fistula/esophageal atresia: Survey results from tracheoesophageal fistula/esophageal atresia online communities. Eur J Pediatr Surg. 2015; 26:476-80.

21. Gallo G, Zwaveling S, Groen H, Van der Zee D, Hulscher J. Long-gap esophageal atresia: A meta-analysis of jejunal interposition, colon interposition, and gastric pull-up. Eur J Pediatr Surg. 2012; 22:420-5.

22. Spitz L, Kiely E, Pierro A. Gastric transposition in children-a 21-year experience. J Pediatr Surg. 2004; 39:27681.

23. Hirschl RB, Yardeni D, Oldham K, Sherman N, Siplovich L, Gross E, et al. Gastric transposition for esophageal replacement in children. Ann Surg. 2002; 236:1.

24. Rintala RJ, Sistonen S, Pakarinen MP. Outcome of oesophageal atresia beyond childhood: J Pediatr Gastroenterol Nutr. 2011; 52:S35-6.

25. Dittrich R, Stock P, Rothe K, Degenhardt P. Pulmonary outcome of esophageal atresia patients and its potential causes in early childhood. J Pediatr Surg. 2017; 52:1255-9.

26. Davenport M, Hosie GP, Tasker RC, Gordon I, Kiely EM, Spitz L. Long-term effects of gastric transposition in children: A physiological study. J Pediatr Surg. 1996; 31:588-93.

27. Molinaro F, Angotti R, Bindi E, Pellegrino C, Casini L, Messina M, et al. An European multicentric study of esophageal replacements: gastric pull-up, jejunal interposition, colonic interposition. Allied J Clin Path. 2017; 1:912.

28. Ludman L, Spitz L. Quality of life after gastric transposition for oesophageal atresia. J Pediatr Surg. 2003; 38:53-7. 